\title{
Style Influences And JSE Sector Returns: Evidence From The South African Stock Market
}

\author{
Wayne Small, University of the Western Cape, South Africa
}

Heng-Hsing Hsieh, University of the Western Cape, South Africa

\begin{abstract}
A distinctive phenomenon on the Johannesburg Stock Exchange (JSE) is the market segmentation between the resource sector and the financial and industrial sectors documented in empirical literature. The dominance of the resource sector in the cap-weighted FTSE/JSE All-Share index (ALSI) implies that the ALSI index might not be mean-variance efficient due to the potential lack of diversification. We estimate and compare the historical sector exposures of the ALSI index to its hypothetically optimal sector exposures over the examination period from 2003 through 2013. It is found that to achieve mean-variance efficiency on the JSE over the examination period, one should maintain substantial investments in the industrial sector and tactically allocate the remainder of the investments to the financial sector and/or the resource sector. It is also observed that the sector exposures of the ALSI index have shifted significantly from the resource sector to the industrial sector. To gain a better understanding of the investment style influences on the JSE sector returns, we further investigate the exposures of the prominent JSE sector returns to the style risks using the Carhart (1997) four-factor model. It is found that investments in financial stocks are exposed to significant value risk and, to some degree, influenced by the performance of large caps on the JSE. In addition, excess returns on the industrial sector are attributed to value, small cap and momentum risk premiums to some degree. The performance of the resource sector, on the other hand, is mildly biased towards the growth, large cap and contrarian investment styles on the JSE.
\end{abstract}

Keywords: Johannesburg Stock Exchange (JSE); Style Anomalies; Efficient Market Hypothesis (EMH); Portfolio Optimization; Asset Pricing Models; Market Segmentation

\section{BACKGROUND}

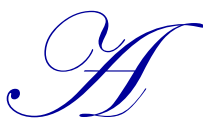

sset pricing can be defined as a scientific process of estimating the intrinsic value of an asset based on its ability to generate future cash flows. Future cash flows are generally weighted by relevant risk factors inherent in the asset that affect the probabilities of realising these cash flows within specific time periods. Investors are assumed to be risk-averse \& demand higher returns (and hence lower prices) from riskier assets as compensation for the additional risks borne in these investments. Building on the assumption of market efficiency and the principle of diversification that underpin modern portfolio theory (MPT) of Markowitz (1952, 1959), the capital asset pricing model (CAPM) developed independently by Sharpe (1964), Lintner (1965) and Mossin (1966), is a well-recognized tool for modelling risk-return trade-off in the investment universe. The mathematical representation of the CAPM is depicted in Equation 1.

$$
R_{i}=R_{f}+\beta_{i, m} \times\left(R_{m}-R_{f}\right)
$$

Under the framework of the CAPM, the only relevant risk to investors is the common market risk proxied by the market risk premium, $R_{m}-R_{f}$. The market risk premium is expressed as the market portfolio's return, $R_{m}$ in excess of the return on a risk-free investment, $R_{f}$. The impact of the changes in the market risk premium is assumed to be systematic in nature and affects the performance of all assets operating in the investment universe. The sensitivity of an asset's return (for instance, the return on a hypothetical asset $i, R_{i}$ ) to changes in the market risk premium is defined as the beta coefficient, $\beta_{i, m}$. Thus, all assets should earn a return that is equal to the risk-free rate at the 
minimum, and increase as a function of their beta coefficients. All other factors that are firm-specific in nature are assumed to be unsystematic and can be mitigated effectively by holding a well-diversified portfolio.

The Johannesburg Stock Exchange (JSE) in South Africa is historically dominated by the resource sector. One of the major challenges of asset pricing on the JSE is that the performances of resource stocks are driven by a different set of macroeconomic forces compared to stocks in other sectors. This phenomenon is commonly referred to as market segmentation on the JSE. The failure of the common market risk, measured by the beta coefficient of the CAPM to explain the JSE stock returns compared to sector-based risk measures is observed in earlier studies conducted by Campbell (1979), Bowie and Bradfield (1993) and Ward (1994). To address this challenge, multifactor models developed from the arbitrage pricing theory (APT) that segregates the market risk into pervasive sector-based risk factors could be adapted to explain the JSE stock returns more effectively. A two-factor APT model, proposed by van Rensburg and Slaney (1997), is introduced to capture sector-specific risks using the JSE All-Gold index and the JSE Industrial index as duel risk proxies. This model is subsequently updated in 2002 to take into account the impact of the JSE sector reclassification to include the unanticipated return movements in the JSE Resource index (RESI) and the JSE Financial-Industrial index (FINDI) as the new explanatory variables (van Rensburg, 2002).

The dominance of the resource sector on the JSE also leads to a potential lack of diversification in the cap-weighted FTSE/JSE All-Share index (ALSI), which is often employed as the market proxy in the CAPM for asset pricing on the JSE. In addition, the noisy market hypothesis of Siegel (2006) suggests that trading noises due to investor overreaction could potentially lead cap-weighted indexes to be sub-optimal as it has the tendency to overweight overvalued assets and underweight undervalued assets. This phenomenon is more serious for the ALSI index as noise trading on the JSE as an emerging market is deemed to be more severe compared to developed capital markets. Thus, the disproportional sector representation in the ALSI index may have negative implications on its mean-variance efficiency as the market proxy on the JSE.

The inadequacy of the CAPM in explaining stock returns also stems from a vast volume of evidence pertaining to persistent abnormal returns generated by the value, small cap and momentum investment styles when pricing assets using the CAPM. These CAPM anomalies are addressed by style-based asset pricing models such as the FamaFrench (1993) three-factor model and the Carhart (1997) four-factor model that recognizes the inherent risks in style investing and adequate risk premiums required by investors who pursue these investment styles. Style investing and sector allocation strategies are often correlated since asset allocation according to sectors inevitably adopts the attributes of a particular combination of investment styles (Vardharah \& Fabozzi, 2007). For instance, most of the financial stocks are regarded as value stocks during the subprime crisis; and during the technology bubble, investments in I.T. stocks mimic the growth investment style.

This paper revisits the impact of market segmentation on the JSE by examining the discrepancies between the historical and optimal sector exposures of the ALSI index; and investigates the style influences on the JSE prominent sector returns over the period from 1 January 2003 to 31 December 2013. Test results provide insights into asset allocation decisions for investors on the JSE.

\section{MARKET SEGMENTATION ON THE JSE}

A unique feature of the JSE is that more than one security market line (SML) exists in the stock market. Campbell (1979) finds that the beta coefficient of the industrial index declines from the mid-1960s to the mid-1970s relative to the beta coefficient of the Gold Index that rises over the same period. Similar evidence is found for individual stocks within each index. Campbell (1979) argues that different economic forces affect stocks from different sectors and proposes that separate market proxies should be employed for pricing stocks from different sectors. Bowie and Bradfield (1993) corroborate Campbell's (1979) findings and argue that the ALSI index is an inappropriate market proxy for pricing assets on the JSE. Study results of Campbell (1979) and Bowie and Bradfield (1993) imply that due to the dominance of the mining companies on the JSE in terms of market capitalization, the performance of the ALSI index is primarily driven by large mining stocks, especially the gold and diamond firms. Thus, it would be impractical to employ the ALSI index as the market proxy to estimate the returns of non-mining stocks. 
In recognition of the market segmentation phenomenon on the JSE, van Rensburg and Slaney (1997) introduce a two-factor model built on the principles of the arbitrage pricing theory (APT). The JSE Actuaries All-Gold index and the JSE Actuaries Industrial index are identified as the most prominent sectors over the period from 1985 to1995 using a factor analytic approach. These two sector indexes are employed as dual proxies in their two-factor APT model. The two-factor model provides superior explanatory power to the CAPM on the JSE over the examination period. The authors further argue that different sources of risk are rewarded with separate risk premiums and that the large majority of the JSE stocks are either influenced by the risk premium in the mining sector or the risk premium in the industrial sector, but not both. While Bowie and Bradfield (1993) propose that an appropriate sector index be employed in the CAPM, van Rensburg and Slaney (1997) argue that the two-factor APT captures all the benefits of the two SML approach proposed by Bowie and Bradfield (1993) and thus is a more appropriate model to explain stock returns on the JSE.

In 2000, the Johannesburg Stock Exchange was renamed as the Johannesburg Securities Exchange and sectors were reclassified. The All-Gold sector and other mineral sub-sectors were subsumed into the resource sector. In addition, Chemicals, Oil, Paper, and Steel sub-sectors were reclassified from the industrial sector and included in the resource sector as well. van Rensburg (2002) updates the work of van Rensburg and Slaney (1997) and motivates that the resource sector index (RESI) and the combined financial-industrial sector index (FINDI) be employed as the new proxies in the two-factor APT model.

\section{RECENT SOUTH AFRICAN LITERATURE ON STYLE RISKS}

Basiewicz and Auret (2010) examine the practicality of employing the Fama-French (1993) three-factor model on the JSE over the period 1992 to 2005. Test results reveal that the Fama-French (1993) three-factor model is able to explain both the value and size effects on the JSE over the examination period. They also find that the Fama-French (1993) three-factor model has greater power in explaining return variations on the JSE relative to the standard CAPM. Auret and Cline (2011) evaluate the inter-relationship between the value, size and January effect over the period from 1988 to 2006. Their study results indicate that no significant value, size or January effects exist over the examination period.

Hsieh and Hodnett (2011) test the overreaction hypothesis on the JSE over the period from 1993 through 2009. Significant mean reversion is documented for winner and loser portfolios with a 36-month formation period. In addition, the degree of mean reversion is found to be cyclical and in relation to the South African business cycle. Test results further suggest that contrarian investing in South Africa appears to be resilient during turbulent times.

Muller and Ward (2013) examine the well-documented anomalies found in international and South African studies. Their research is motivated by the fact that local studies suffer from methodological shortcomings. The authors extend their examination period from 1985 to 2011 and rebalance their style portfolios every quarter with financial year-end data lagged by 3 months. In addition, only the top 160 firms ranked by market capitalization are included in their study to mitigate liquidity constraints. The style portfolios that show significant abnormal returns include portfolios formed by momentum, liquidity, return on capital, return on equity, interest cover and a variety of value indicators. Contrary to other reported empirical evidence on the size effect, their portfolios formed on the basis of firm size only outperform the ALSI over the period from 2000 to 2002. The size effect disappears thereafter. They argue that a premium for illiquidity dissipates after the restructuring of the JSE in early 2000.

Bhana (2014) investigates the value-growth phenomenon on the JSE over the period from 1997 to 2012 and finds that the value portfolios outperform their growth counterparts on a risk-adjusted basis. In addition, the outperformance of the value portfolios becomes more prominent for longer holding periods. The author further argues that the superior performance of the value investment style is attributed to investor behaviors and agency costs of investment management rather than the higher risk inherent in value stocks.

Hodnett (2014) examines the cyclical nature of the value-growth phenomenon on the JSE over the period from 1997 to 2013. The benchmarks used to distinguish value and growth stocks include earnings/price ratio, book/price ratio and sales/price ratio. It is found that classification of value and growth stocks using the sales/price ratio is most volatile and could be reflective of the market sentiment. In addition, study results also reveal the predictive power of 
value-growth spreads in forecasting near-term market risk premiums on the JSE in that a significantly positive correlation is found between value-growth spreads and the forward market risk premium. Hsieh (2015) investigates whether the value effect is persistent on the JSE when firm size is controlled for over the period from 1997 to 2013 using the same value-growth benchmarks as Hodnett (2014). The value effect is found to be weak within each firm size segment. In addition, the size effect is found to be significant regardless of the value or growth tilt of the portfolios. The study concludes that the value effect is dominated by the size effect on the JSE.

\section{RESEARCH METHODOLOGY}

Stocks listed on the JSE could be broadly categorized into three prominent sectors, namely the financial sector, the industrial sector and the resource sector. As a cap-weighted index, the performance of the ALSI index (the market proxy) is primarily driven by the large caps in these sectors. The tradable indexes representing the three prominent sectors include the FINI Top 15 index (FINI), the INDI Top 25 index (INDI) and the RESI Top 10 index (RESI) respectively. The performance of the market proxy and the prominent sector indexes over the examination period from 1 January 2003 to 31 December 2013 are evaluated based on their returns, standard deviations, beta coefficients as well as traditional risk-adjusted measures such as the Sharpe ratio, Treynor measure and Jensen's alpha. To gain a better understanding of the co-movements between the prominent sectors on the JSE, the return correlations of the sector indexes are analysed.

In order to evaluate the discrepancies between the historical and optimal sector exposures of the ALSI index, the historical sector exposures of the ALSI index are estimated and compared to its optimal sector exposures that maximize the Sharpe ratio of the ALSI index using similar optimization procedures proposed by Yu (2008) and Hsieh, Hodnett and van Rensburg (2012).

\subsection{Estimating the Historical Sector Exposures of the ALSI Index}

Using the return-decomposition model of Sharpe (1992), the ALSI return can be decomposed and attributed to its historical exposures in the tradable sector indexes as shown in Equation 2.

$$
R_{M}=\left(\hat{\theta}_{M, F I N I} \times R_{F I N I}\right)+\left(\hat{\theta}_{M, I N D I} \times R_{I N D I}\right)+\left(\hat{\theta}_{M, R E S I} \times R_{R E S I}\right)+\hat{\varepsilon}_{M}
$$

$R_{M}, R_{F I N I}, R_{I N D I}$ and $R_{R E S I}$ represent the returns on the ALSI, FINI, INDI and RESI indexes. $\hat{\theta}_{M, F I N I}, \hat{\theta}_{M, I N D I}$ and $\hat{\theta}_{M, R E S I}$ are estimates of the ALSI's historical exposures to FINI, INDI and RESI. An optimization procedure is implemented using the 12 monthly index returns every year over the examination period from 2003 through 2013 with the objective of searching for the sector exposures that result in the variance of the regression error, $\left(\hat{\varepsilon}_{M}\right)^{2}$ being minimized. To ensure that the ALSI return is fully and positively attributed to the constituent sector indexes, constraints are imposed to restrict the sum of the sector exposures to equal to 100 percent and only positive estimates are permitted in the optimization procedure.

\subsection{Estimating the optimal sector exposures of the ALSI index}

To estimate the annual optimal sector compositions of the ALSI index, an optimization procedure similar to the one proposed by $\mathrm{Yu}$ (2008) and Hsieh, Hodnett and van Rensburg (2012) is implemented with the goal of maximizing the monthly Sharpe ratio of the ALSI index. The monthly Sharpe ratio for the market proxy $M$ in year $T$ is expressed in Equation 3.

$$
\text { Sharpe } \text { Ratio }_{P, T}=\left(\bar{R}_{P, T}-\bar{R}_{f, T}\right) / \sigma_{P, T}
$$

$\bar{R}_{P, T}$ represents the average monthly returns for the optimal portfolio $P$ in year $T$; and $\bar{R}_{f, T}$ represents the average monthly returns for the risk-free proxy in year $T$. The monthly returns for the optimal portfolio are computed using Equation 2 above. The risk-free proxy employed in this research is the 90-day South African Treasury bill. The denominator $\sigma_{P, T}$ is the standard deviation of the monthly returns for the optimal portfolio in year $T$. As expressed by Equation 3, the Sharpe ratio is a reward-to-risk measure. By maximizing the Sharpe ratio of the portfolio, the 
highest excess return is achieved per unit of portfolio risk. The optimal sector exposure in year $T$ represent the weights, $\hat{\theta}_{M, F I N I}, \hat{\theta}_{M, I N D I}$ and $\hat{\theta}_{M, R E S I}$ in Equation 2 that maximizes the Sharpe ratio depicted in Equation 3. Similarly to the restrictions imposed in Section 4.1, the sum of the sector exposures is set to equal to 100 percent and negative weights are prohibited in the optimization procedure.

\subsection{Estimating the Style Exposures of the JSE Prominent Sectors}

To gain a better understanding of the investment style influences on the JSE sector returns, we estimate the exposures of the prominent JSE sector returns to the risk factors specified in the Carhart (1997) four-factor model over the examination period. As depicted by Equation 4, the Carhart (1997) four-factor model decomposes the excess returns of the JSE tradable sector indexes and attributes the excess returns of the indexes to the market risk and a series of investment style risks. The market risk is represented by the market risk premium originated from the CAPM; and the investment style risks refer to the sector's tilts towards value stocks, small caps and momentum stocks on the JSE.

$$
R_{X, t}-R_{f, t}=\alpha_{X}+\beta_{X}\left(R_{m, t}-R_{f, t}\right)+h_{X} H M L_{t}+s_{X} S M B_{t}+w_{X} W M L_{t}+\varepsilon_{X, t}
$$

$R_{X, t}-R_{f, t}$ represents the excess return on the tradable index $X$ in month $t$ and $R_{m, t}-R_{f, t}$ represents the market risk premium in month $t . H M L_{t}, S M B_{t}$ and $W M L_{t}$ are the style risk premiums on the value, small caps and momentum investment styles in month $t$. The value risk premium, denoted as $H M L$ and known as high-minus-low, is calculated as the return difference between the high and low book-to-market value quartile portfolios constructed from the ALSI constituents. On the other hand, the small cap risk premium, denoted as $S M B$ and known as small-minus-big, is calculated as the return difference between the small cap quartile and the large cap quartile portfolios. Similarly, the momentum risk premium, denoted as $W M L$ and known as winner-minus-loser, is calculated as the return difference between the quartile portfolios of prior 12-month winners and prior 12-month losers on the JSE. The style portfolios are equally-weighted and rebalanced monthly throughout the examination period. According to empirical evidence, higher risks and thus higher expected returns are associated with exposures to value stocks, small caps and prior short-term winning stocks relative to investments in growth stocks, large caps and prior short-term losers.

\section{EMPIRICAL FINDINGS}

The performance statistics of the ALSI index and the tradable sector indexes on the JSE over the examination period are presented in Table 1. The ALSI index, as the market proxy, has a moderate annualized return of 17.36 percent; moderate total risk of 16.93 percent as measured by the standard deviation and the average systematic risk of 1.0 measured by the beta coefficient. The RESI index has the lowest return of 12.92 percent; with above-average standard deviation of 25.53 percent and beta coefficient of 1.30. Consequently, the RESI index underperforms the market proxy in all three risk-adjusted performance measures. On the other hand, the INDI index has the highest return of 23.95 percent with the lowest standard deviation of 16.18 percent and below-average beta coefficient of 0.74 , which makes it the best performing index on a risk-adjusted basis. The FINI index earns a lower return (14.94 percent) compared to the ALSI index with a moderate standard deviation of 17.39 percent and underperforms the ALSI in terms of the Sharpe ratio. However, the FINI index has the lowest beta coefficient of 0.64, which leads to a higher Treynor measure and a positive Jensen's alpha compared to the ALSI index.

Table 1. Sector Performance Statistics (Annualized)

\begin{tabular}{l|c|c|c|c}
\hline & \multicolumn{4}{|c}{ Basic Performance Statistics } \\
\hline & FINI & INDI & RESI & ALSI \\
\hline Arithmetic Return & $14.94 \%$ & $23.95 \%$ & $12.92 \%$ & $17.36 \%$ \\
\hline Standard Deviation & $17.39 \%$ & $16.18 \%$ & $25.53 \%$ & $16.93 \%$ \\
\hline Beta Coefficient & 0.64 & 0.74 & 1.30 & 1.00 \\
\hline Sharpe Ratio & & \multicolumn{2}{|c|}{ Risk-Adjusted Performance Statistics } & \\
\hline Treynor Measure & 0.415 & 1.002 & 0.203 & 0.569 \\
\hline Jensen's Alpha & 0.113 & 0.219 & 0.040 & 0.094 \\
\hline
\end{tabular}


The return correlations between the indexes are presented in Table 2. It is noted that the ALSI index has much stronger return correlations with the RESI index (0.92) and the INDI index (0.83) compared to its return correlation with the FINI index (0.66). The highest return correlation (0.92) between the market proxy and the RESI index is indicative of the dominance of the resource sector on the JSE. While both the RESI index and the INDI index have strong return correlation with the market proxy, their return correlation with each other is only 0.58 . On the other hand, the FINI index has return correlations of 0.76 with the INDI index and 0.40 with the RESI index respectively. The analysis of the sector correlation matrix suggests that while sector indexes have moderate or strong return correlations with the market proxy, the return correlations among the sector indexes are at most moderate. This implies that the market segmentation phenomenon continues to persist on the JSE, and hence sector allocation strategy on the JSE has an important role to play in diversifying sector-specific risks. The substantially low return correlation of 0.40 between the FINI sector and the RESI sector suggests that sector rotation between the financial and resource sectors could be an effective market timing approach.

Table 2. Sector Correlation Matrix

\begin{tabular}{l|c|c|c|c}
\hline & FINI & INDI & RESI & ALSI \\
\hline FINI & 1.00 & & & \\
\hline INDI & 0.76 & 1.00 & & \\
\hline RESI & 0.40 & 0.58 & 1.00 & 1.00 \\
\hline ALSI & 0.66 & 0.83 & 0.92 & \\
\hline
\end{tabular}

Figure 1 shows the historical sector exposures of the ALSI index estimated using Equation 2 over the entire examination period from 1 January 2003 to 31 December 2013. The dominance of the resource sector on the JSE can be observed from the ALSI index's substantial resource sector exposure of $47.68 \%$ over the examination period. The ALSI index has the lowest sector exposure of $14.86 \%$ to the movements in the financial sector on the JSE over the examination period.

Figure 1. Sector Exposures of the ALSI Index (2003 to 2013)

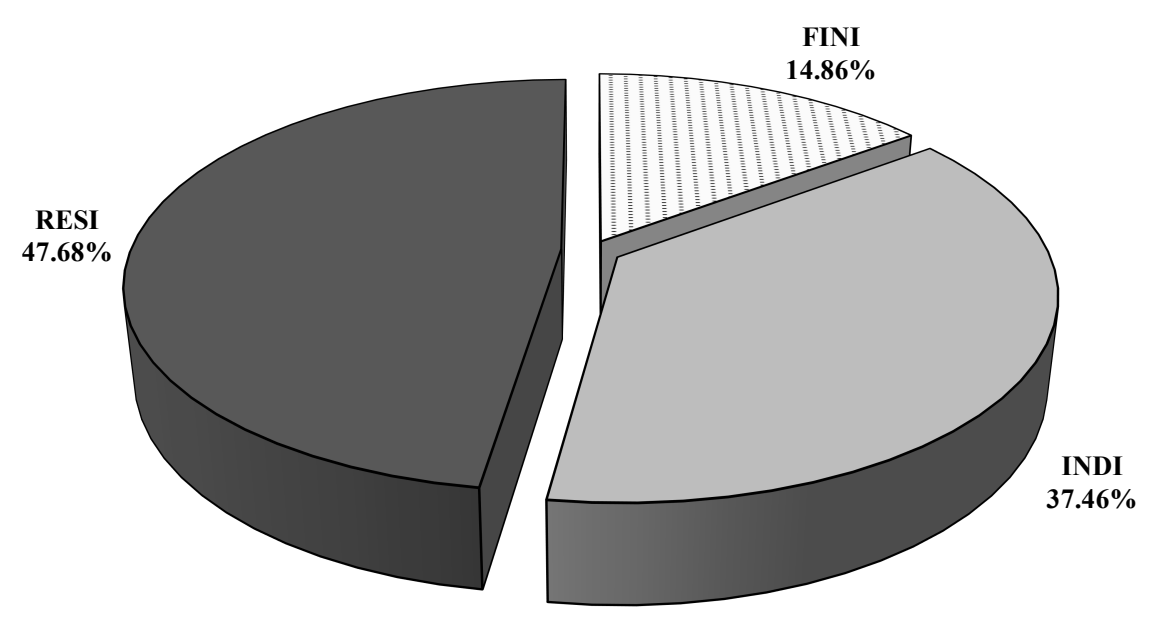

Figure 2 illustrates the historical sector exposures of the ALSI index estimated using Equation 2 on a year-on-year basis over the examination period. The annual historical sector exposures of the ALSI index measure the sensitivities of the ALSI index return to changes in the returns of the respective sectors. Since the ALSI index is a cap-weighted index, its sector exposures will fluctuate in tandem with the relative sector performances from year to year. When a sector performs relatively better (worse) than other sectors, its market capitalization increases 
(decreases) relative to other sectors, which increases (decreases) its influences on the cap-weighted ALSI index returns. Thus, historical changes in the sector exposures of the ALSI index represent the relative performances of the respective sectors over the examination period. Observing the annual historical sector exposures of the ALSI index in Figure 2 reveals that the South African stock market has undergone a transformation from its substantial exposure of $50 \%$ to the movements in the resource sector in 2003 to less than $40 \%$ exposure to the movements in the resource sector in recent years. The position of the resource sector became even more fragile as mining firms battled to maintain their production since the Marikana mine violence in 2012 with frequent strike actions in the mining industry. The slump in commodity prices led by weaker global demand and slower Chinese economy also adds pressure to the resource sector in recent years. The industrial sector, on the other hand, has gradually become the main driver of the ALSI index performance over the examination period. For the South African economy to maintain sustainable growth, the country can no longer rely on the export of its rich commodities. The contributions of the industrial and tertiary sectors has become critical to the country's economic growth and employment generation. Over the examination period, the financial sector loses tremendous value during the global financial crisis in 2007 and 2008. Although the sector rebounded drastically in 2009 and 2010 from its trough, the ALSI index's exposure to the performance of the financial sector remains less than $20 \%$ in recent years.

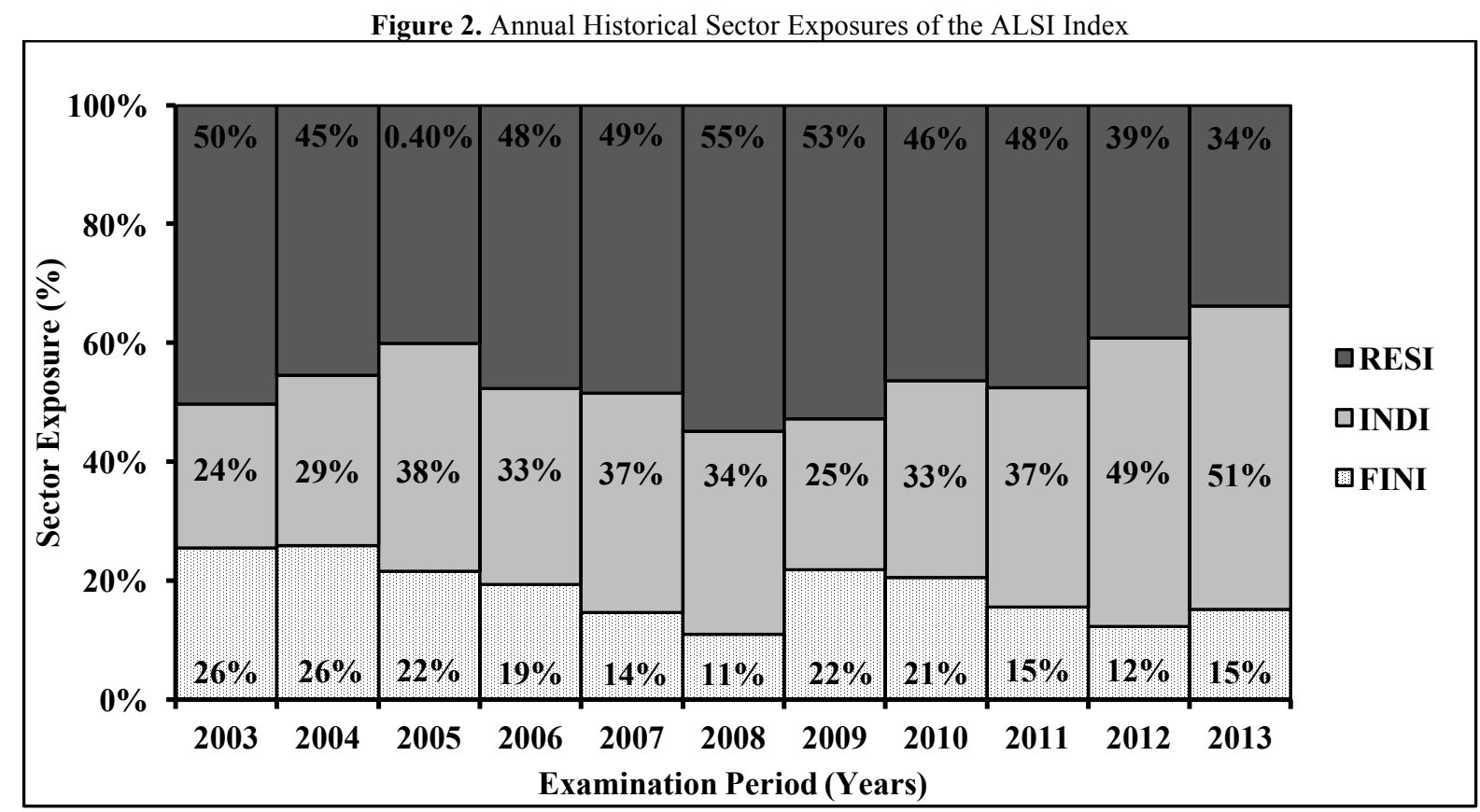

Figure 3 shows the annual optimal sector exposures of the ALSI index that maximizes the Sharpe ratio depicted by Equation 3. The annual optimal exposures indicated in Figure 3 suggest that there are potential benefits to tactically allocate funds into the financial sector and/or resource sector, but the greatest portion of the equity investment should stay in the industrial sector most of the time. With the exception of 2004 and 2008, an investor should maintain more than 50 percent of his/her South African equity investment in the industrial sector to achieve meanvariance efficiency. It is also apparent that the best sector allocation strategy in 2003, 2010, 2011 and 2013 is the one that allocates 100 percent of the capital in the industrial sector. 
Figure 3. Annual Optimal Sector Exposures of the ALSI Index

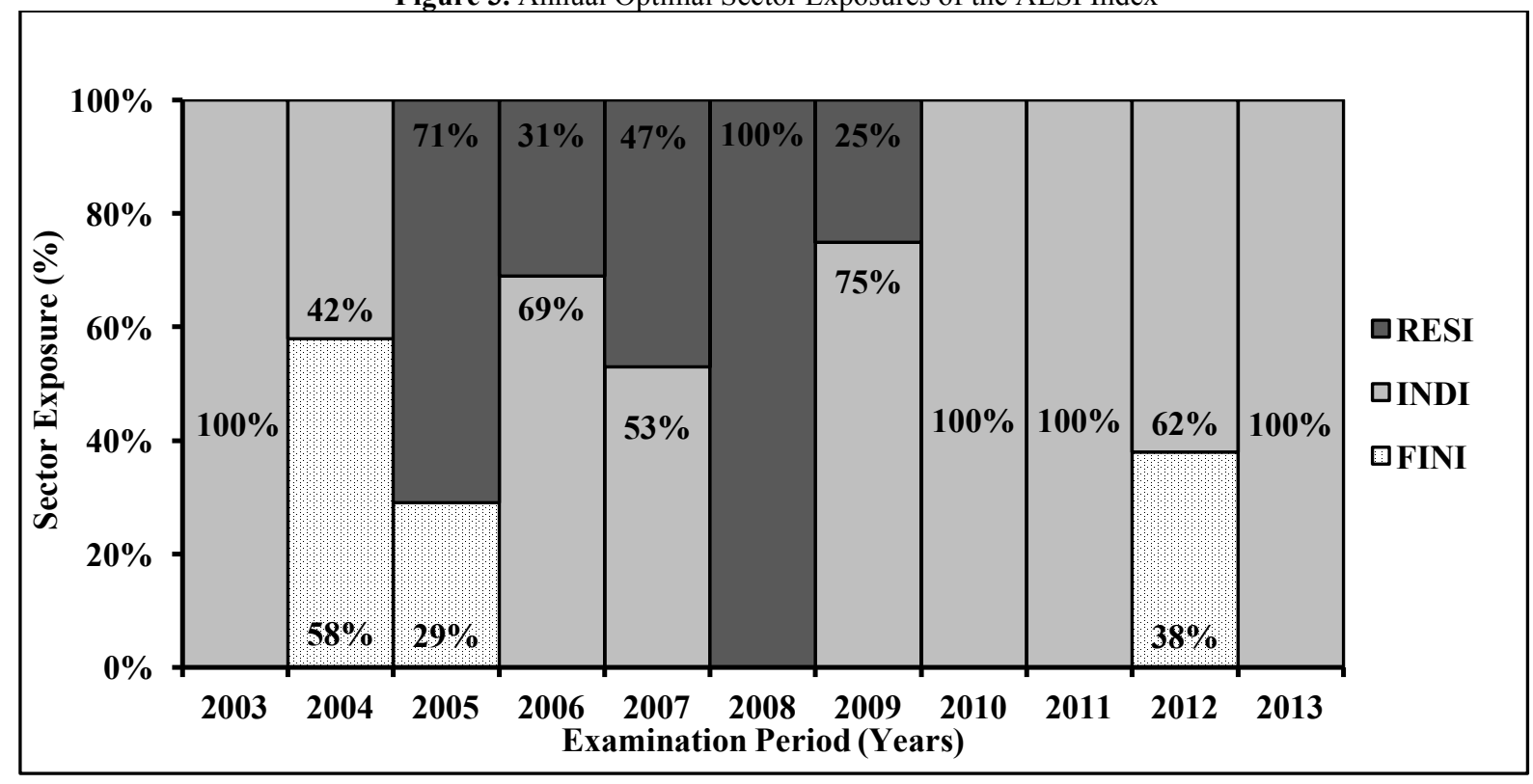

Table 3 demonstrates the sector exposures to style risk factors over the examination period estimated using Equation 4 (that is, the Carhart (1997) four-factor model). Factor loadings that are statistically significant at 1 percent, 5 percent and 10 percent levels are labelled with three asterisks $(* * *)$, two asterisks $(* *)$ and one asterisks $(*)$ respectively. The fact that none of the regression constant (that is, alpha) is statistically significant suggests that the Carhart (1997) four-factor model has effectively explained the movements in the prominent sector returns. The 1 percent statistical significance of the factor loadings on the market risk premium for all three sectors indicates that the market risk remains the most important risk factor that systematically drives the returns in all three prominent sectors on the JSE. The exposure of the financial sector returns to movements in the value risk premium is the only statistically significant factor loading on style risks. A value bias for the financial sector performance means that the returns of financial stocks are driven by the performance of value stocks on the JSE. It is also observed that the financial sector has a mild bias towards large caps as indicated by the insignificantly negative factor loading on the small cap risk premium. For the industrial sector, the factor loadings on all three style risk premiums are insignificantly positive. This suggests that investments in South African industrial stocks, to some degree, are exposed to value, small cap and momentum risks. On the other hand, the resource sector has negative factor loadings to all three style risk premiums. Although these exposures are statistically insignificant, an examination of the $t$ statistics of the style exposures indicates that the performance of the resource sector has a mild tilt towards the growth, large cap and contrarian investment styles on the JSE. Overall, the Carhart (1997) four-factor model explains 70 percent and 85.3 percent of the variations in the excess returns of the INDI and RESI indexes respectively. By contrast, only 48.2 percent of the variations in the excess returns of the FINI index is explained by the model even when the style risks are accounted for. The financial sector not only has relative lower correlations with other prominent sectors, the relatively lower ability of the Carhart (1997) regression in explaining the financial sector performance indicates that investing in the financial sector of the JSE has the potential to capture different dimensions of risks that are not inherent in the other sectors. 
Table 3. Carhart (1997) Four-Factor Model Regression Results

\begin{tabular}{|c|c|c|c|}
\hline & FINI & INDI & RESI \\
\hline R-Square & 0.482 & 0.700 & 0.853 \\
\hline Alpha & 0.000 & 0.005 & -0.003 \\
\hline$t$-statistic ${ }_{\text {alpha }}$ & 0.066 & 1.705 & -0.894 \\
\hline b_MRP (market risk premium) & $0.640^{* * *}$ & $0.773^{* * *}$ & $1.285^{* * *}$ \\
\hline$t$-statistic & 9.369 & 15.945 & 24.213 \\
\hline b_HML (value risk premium) & $0.257^{*}$ & 0.091 & -0.090 \\
\hline$t$-statistic & 2.504 & 1.259 & -1.125 \\
\hline b_SMB (small cap risk premium) & -0.051 & 0.055 & -0.010 \\
\hline$t$-statistic & -0.562 & 0.852 & -0.147 \\
\hline b_WML (momentum risk premium) & 0.000 & 0.056 & -0.081 \\
\hline$t$-statistic & -0.007 & 1.198 & -1.588 \\
\hline
\end{tabular}

\section{CONCLUSION}

The performance analysis of the prominent sectors on the JSE reveals that the industrial sector is the best performing sector on the JSE over the examination period. Consequently, an examination of the annual optimal sector exposures of the ALSI index reveals that investors should maintain a substantial proportion of their assets in the industrial sector to achieve mean-variance efficiency over the examination period. Although the return correlation between the ALSI index and the resource sector remains highly significant (92 percent), the dominance of the resource sector on the JSE has deteriorated significantly over the last decade. The annual historical exposure of the ALSI index to the movements in the resource sector has declined substantially from 50 percent in 2003 to a mere 34 percent in 2013 . By contrast, the ALSI index's exposure to the industrial sector has grown significantly from 24 percent in 2003 to 51 percent in 2013. The recent uncertainties in the resource sector suggests that sustainable economic growth and employment generation will not be achieved without shifting the country's reliance from mining exports to industrial manufacturing and tertiary sectors. This is especially true when the mining production is halted by local strike actions and commodity prices are slumped due to sluggish global demand in recent years. The financial sector, on the other hand, is less exposed to systematic risks as indicated by the sector's low return correlation with the ALSI index relative to other sector indexes. In addition, the Carhart (1997) four-factor model has the lowest explanatory power for the variations in the excess return of the FINI index. The financial sector also has low return correlations with the other two sectors. These findings imply that the financial sector has the ability to capture different dimensions of risks that are not exposed by other sectors and allocations to financial stocks on the JSE could provide potential risk premiums that are unavailable to investments in other sectors. Examining the annual optimal compositions of the ALSI index over the examination period further suggests that investors can potentially benefit from tactical allocations into the financial sector and/or the resource sector. The style attribution analysis using the Carhart (1997) four-factor model further reveals that the financial sector has a statistically significant bias towards the value investment style on the JSE. In addition, an insignificantly negative factor loading on the small cap risk premium is also detected for the FINI index, suggesting some large cap influence on the performance of the financial stocks on the JSE. With regard to investments in the industrial sector, it is found that the sector's performance is, to some degree, positively influenced by the value, small cap and momentum investment styles on the JSE. The performance of the resource sector, on the other hand, has a mild tilt towards the growth, large cap and contrarian investment styles on the JSE.

\section{ACKNOWLEDGEMENT}

We thank the research office of the University of the Western Cape for their support, and Prof. Kathleen Hodnett for her valuable comments.

\section{AUTHOR BIOGRAPHIES}

Mr. Wayne Small, M.Com is a Finance lecturer in the School of Business and Finance at the University of the Western Cape, South Africa. 
Prof. Heng-Hsing Hsieh, PhD, CFA is the Deputy Dean of Research in the Faculty of Economics and Management Sciences at the University of the Western Cape, South Africa. He is a member of the International Institute of Forecasters (IIF), a member of the South African Institute of Financial Markets (SAIFM) and a statistical consultant registered on the expert list of the South African Statistical Association. E-mail: ahsieh@uwc.ac.za. Corresponding Author

\section{REFERENCES}

Auret, C. \& Cline, R. (2011). Do the value, size and January effects exist on the JSE? Investment Analysts Journal, 74, 29-37.

Basiewicz, P.G. \& Auret, C. J. (2010). Feasibility of the Fama and French Three Factor Model in Explaining Returns on the JSE. Investment Analysts Journal, 71, 13-23.

Bhana, N. (2014). Value versus growth share returns: the case for companies listed on the Johannesburg Stock Exchange. International Journal of Finance \& Policy Analysis, 6(1-2), 36-48.

Bowie, D. C. \& Bradfield, D. J. (1993). A review of systematic risk estimation on the JSE. De Ration, 7(1), 6-22.

Cambell, G. (1979). Risk and return on the Johannesburg Stock Exchange. University of the Witwaterstrand. Unpublished MBA thesis.

Carhart, M. M. (1997). On persistence in mutual fund performance. Journal of Finance, 52(1), 57-82.

Cavaglia, S. \& Moroz, V. (2002). Cross-industry, cross-country allocation. Financial Analyst Journal, 58(6), 78-97.

Fama, E. F. \& French, K. R. (1993). Common risk factors in the returns on stocks and bonds. Journal of Financial Economics, $33(1), 3-56$.

Hsieh, H. \& Hodnett, K. (2011). Tests of the overreaction hypothesis and the timing of mean reversals on the JSE Securities Exchange (JSE):The case of South Africa. Journal of Applied Finance \& Banking, 1(1), 107-130.

Hsieh, H., Hodnett, K. \& van Rensburg, P. (2012). Do managers of global equity funds outperform their respective style benchmarks? Evidence from South Africa. International Business and Economics Research Journal, 11 (3): 269-282.

Hsieh, H. (2015). Empirical investigation of the value effect in the large and small cap segments of the JSE: evidence from the South African stock market. Investment Management and Financial Innovations, 12(4), 16-22.

Hodnett, K. (2014). Value-growth timing: Evidence from the Johannesburg Stock Exchange. The Journal of Applied Business Research, 30(6), 1939-1946.

Lintner, J. (1965). The valuation of risky assets and the selection of risky investments in stock portfolios and capital budgets. Review of Economics and Statistics, 47(1), 13-37.

Markowitz, H.M. (1952). Portfolio Selection. Journal of Finance, 7(1), 77-91.

Markowitz, H.M (1959). Portfolio Selection: Efficient Diversification of Investments. New York: Wiley.

Mossin, J. (1966). Equilibrium in a capital asset market. Economietrica, 34(4), 768-783.

Muller, C. \& Ward, M. (2013). Style-based effects on the Johannesburg Stock Exchange: a graphical time-series approach. Investment Analysts Journal, 77, 1-16.

Sharpe, W. F. (1964). Capital asset prices: A theory of market equilibrium under conditions of risk. Journal of Finance, 19(3), 425-442.

Sharpe, W. F. (1992). Asset allocation: management style and performance measurement. Journal of Portfolio Management, 18, $7-19$.

Seigel, J. (2006). The noisy market hypothesis. Wall Street Journal, June 14.

van Rensburg, P. \& Slaney, K. B. E. (1997). Market segmentation on the Johannesburg Stock Exchange. Journal of Studies in Economics and Econometrics, 23(3), 1- 23.

van Rensburg, P. (2002). Market segmentation on the Johannesburg Stock Exchange II. Journal of Studies in Economics and Econometrics, 26(1), 1-19.

Vardharaj, R. \& Fabozzi, F. J. (2007). Sector, style, region: Explaining stock allocation performance. Financial Analysts Journal, 63(3), 59-70

Ward, M. J. (1994). Risk on the Johannesburg Stock Exchange. De Ratione, 8(2), 99-113.

$\mathrm{Yu}, \mathrm{X}$. (2008). The investigation of style indices and active portfolio construction on the JSE. (Unpublished master's thesis). University of Cape Town, Cape Town, South Africa. 